\title{
Metasemiotic Projects and Lifestyle Media: Formulating Commodities as Resources for Identity Enactment
}

\author{
Evgeni Molodychenko \\ Higher School of Economics National Research University \\ St. Petersburg, Russia
}

\begin{abstract}
There has recently been a notable increase in the amount and perceived significance of new lifestyle media. Besides the instructive and entertaining function, these media arguably play a more fundamental sociocultural role of constructing identities. In consumer societies, these identities are to a great extent enacted through the acquisition of commodities and engagement in commodified practices, which thereby become semiotic resources of identity stylization. The purpose of this article is to explore the discursive mechanisms underpinning the process of formulating commodities and practices as such semiotic resources. To this end, several discourses from new online men's magazines have been analyzed drawing on a model of discourse analysis that sees discourse as one of the "moments" of the social practice it is embedded in. The results indicate that the mechanism behind the processes in question can be described as a metasemiotic project. As such a project unfolds in discourse, various commodities and practices are being typified by a metasemiotic term. One of the most frequent prototypical metasemiotic terms in these resources is stylish man. The term is instantiated in texts by several lexemes, including the lexeme style and its derivatives, as well as lexemes naming various "masculine personas" such as man, guy, kid, gentleman, bad ass. It has been shown that an increasing number of commodities and practices are being "theorized" by the discourse of new online men's magazines and typified by this term. One important feature behind the workings of the metasemiotic project is intertextuality. Specific texts are always dialogically linked to other texts of lifestyle discourse, while object-signs are reformulated and imbued with different social values. These results contribute to the exploration of contemporary lifestyle media and discursive mechanisms of identity construction used by them, and, in a more general sense, to recent discussions of operationalizing wider sociocultural context in textually oriented discourse analysis.
\end{abstract}

Keywords: lifestyle media, identity construction, metasemiotic project, consumerism, masculinity, discourse analysis, intertextuality, the language of appraisal

\section{For citation:}

Molodychenko, Evgeni. 2020. Metasemiotic projects and lifestyle media: Formulating commodities as resources for identity enactment. Russian Journal of Linguistics 24 (1). 117-136. DOI: 10.22363/2687-0088-2020-24-1-117-136. 
Научная статья

\title{
Метасемиотические проекты и лайфстайл-медиа: дискурсивные механизмы превращения предметов потребления в ресурсы выражения идентичности
}

\author{
Е.Н. Молодыченко \\ Национальный исследовательский университет «Высшая школа экономики» \\ Санкт-Петербург, Россия
}

\begin{abstract}
Аннотация
В последние несколько лет наблюдается рост количества и значимости новых лайфстайл-медиа. Помимо чисто инструктирующей и развлекательной функции, такие медиа выполняют и важную социокультурную функцию конструирования идентичностей. В условиях общества потребления идентичности формулируются как выражаемые путем использования товаров и реализации коммерциализированных практик. Целью настоящего исследования является описание дискурсивных механизмов, лежащих в основе превращения предметов потребления и практик в семиотические ресурсы выражения идентичности. Исследование проводится в соответствии с моделью дискурс-анализа, предполагающей рассмотрение дискурса в его связи с широким экстралингвистическим контекстом. Материалом исследования послужили дискурсы новых онлайн-ресурсов для мужчин, являющиеся одним из ключевых типов современных лайфстайл-медиа. Основным результатом исследования является описание упомянутого выше дискурсивного механизма как метасемиотического проекта. В процессе реализации такого проекта разнородные объекты-знаки - товары и практики - типизируются при помощи метасемиотического термина. Для рассматриваемых ресурсов таким термином является инвариантное выражение «стильный мужчина», выражающее популярную форму идентичности. К основным вариантам текстовой актуализации данного термина следует отнести словоформы с корневой морфемой style, а также лексемы, называющие различные «ипостаси» современного мужчины, вроде man, guy, kid, gentleman и bad ass. Анализ демонстрирует, что с течением времени все большее количество товаров и практик охватывается изучаемым видом дискурса и, соответственно, подводится под указанный типизирующий термин. Ключевая роль в реализации метасемиотического проекта отводится интертекстуальности: конкретные тексты всегда перекликаются с другими текстами лайфстайл-дискурса; объекты-знаки подвергаются в этом процессе бесконечному переформулированию и наполняются новым содержанием. Полученные результаты вносят вклад в изучение современных лайфстайл-медиа, используемых в них механизмов дискурсивного конструирования идентичностей, а также в дальнейшее осмысление процесса изучения дискурса в его связи с социокультурным контекстом.
\end{abstract}

Ключевые слова: лайфстайл-медиа, конструирование идентичности, метасемиотический проект, консьюмеризм, маскулинность, анализ дискурса, интертекстуальность, языковая оценка

\section{Для цитирования:}

Молодыченко Е.Н. Метасемиотические проекты и лайфстайл-медиа: дискурсивные механизмы превращения предметов потребления в ресурсы выражения идентичности // Russian Journal of Linguistics. 2020. T. 24. No 1. C. 117-136. DOI: 10.22363/2687-00882020-24-1-117-136. 


\section{1. Введение}

Одним из основных трендов развития медиаиндустрии последних нескольких лет следует считать беспрецедентный рост лайфстайл-сегмента (Raisborough 2011: 5-6; Talbot 2007: 107). Данный сегмент представлен медиа, ориентированными на обсуждение повседневных практик индивидов, таких как мода и стиль, уход за собой, обустройство жилища, организация досуга, приготовление еды, путешествия и отношения с противоположным полом (Bell \& Hollows 2005b, 2006a). Как известно, лайфстайл-медиа и социальная форма «стиль жизни» (Chaney 2002) начали свою историю достаточно давно (Agha 2007: 215-219; Bell \& Hollows 2006b; Machin \& van Leeuwen 2007: 14). Тем не менее, то, что происходит в последние 8-10 лет, интуитивно воспринимается как нечто совершенно новое: количество лайфстайлмедиа в сети Интернет, продуцирующих лайфстайл-дискурс «культурных посредников» (Featherstone 1987: 66) и размер аудитории растут в геометрической прогрессии.

Такая ситуация может рассматриваться как один из основных факторов, обусловливающих актуальность обращения к лайфстайл-медиа как к объекту исследования. Еще в 2005 году редакторы двух монографий, посвященных изучению лайфстайл-медиа, подчеркивали важность данной задачи и наличие малого количества работ, ее решающих (Bell \& Hollows 2005a). При этом помимо простого роста объема сегмента наблюдаются и специфические трансформации форматов и жанров, используемых данными медиа. Такие трансформации могут быть, в частности, обусловлены перемещением лайфстайл-медиа в Интернет (Lüders, Prøitz, \& Rasmussen 2010) и также требуют изучения.

Имеющиеся работы, далее, преимущественно выполняются в рамках социологических, культурологических и медиаисследовательских подходов. В области же дискурс-анализа, как представляется, лакуна еще более очевидна. При этом мы полагаем, что изучение «каждодневных» дискурсов лайфстайл-сегмента является не менее значимой задачей, чем обращение к традиционным объектам дискурс-анализа, наподобие политического дискурса, ввиду важной социокультурной роли этих «каждодневных» дискурсов.

В чем же проявляется эта социокультурная роль? Помимо реализации инструктирующей функции, лайфстайл-дискурс является одной из движущих сил формирования идентичностей (Raisborough 2011). Как известно, современные концепции идентичности подчеркивают агентивность индивида в ее выборе, конструировании и выражении. Думается, что лайфстайл-дискурс один из основных типов дискурса, выполняющих функцию информирования субъектов о существующих стилях жизни и регламентации правил реализации этих стилей жизни. Следовательно, такой дискурс должен быть востребован на всех трех указанных стадиях. 
В первом приближении регламентирующую «работу» лайфстайл-дискурса можно представить в виде двух взаимосвязанных процессов - процесса превращения предметов потребления в семиотические ресурсы выражения идентичности и процесса агрегации этих ресурсов в готовые лайфстайл-проекты (Agha 2011). Определение того, какие конкретно дискурсивные механизмы эксплуатируются в этих процессах, - одна из потенциально актуальных задач дискурс-аналитического проекта.

Реализация же такого проекта сопряжена как минимум с двумя сложностями. Во-первых, мы утверждаем, что изучение дискурса с целью решения обозначенной задачи предполагает анализ речевого произведения в его обусловленности экстралингвистическими факторами. Думается, что непросто сколько-либо убедительно продемонстрировать роль дискурса в семиотизирующих и инструктирующих процессах, не сформулировав при этом подходящую теорию идентичности, предмета потребления и их взаимосвязи, а также не описав социокультурный контекст возникновения и существования интересующих нас типов медиа ${ }^{1}$. Во-вторых, мы полагаем, что одной из сложностей является выбор модели и метаязыка описания самого дискурса как речевого произведения. То, какие конкретно компоненты содержания, композиции, текстовые стратегии и языковые средства должны стать объектом анализа, чтобы стала возможна демонстрация той самой «погруженности» речевого произведения «в жизнь», также является вопросом, не имеющим, как нам кажется, однозначного ответа.

Из сказанного выше вытекает цุель данной работы. Эта цель заключается в описании дискурсивных механизмов, участвующих в превращении предметов потребления в семиотические ресурсы выражения идентичности как одной из ключевых функций современных лайфстайл-медиа. Решение такой комплексной задачи требует предварительного формулирования адекватной теоретической рамки и метаязыка анализа дискурса в его взаимодействии с социокультурным контекстом. Материалом анализа послужили новые интернет-ресурсы для мужчин, являющиеся популярным и - интуитивно - одним из самых влиятельных подвидов современных лайфстайл-медиа ${ }^{2}$.

\section{2. Стили жизни и дискурс}

Лайфстайл-дискурсом будем называть речевое (мультимодальное) наполнение лайфстайл-медиа. Что же в таком случае следует относить к лайфстайл-медиа? В первой из двух монографий, посвященных изучению

${ }^{1}$ Все это, конечно же, имеет непосредственное отношение к теоретическим дискуссиям на предмет операционализации контекста в дискурсивном исследовании((Blommaert 2005: 37, 39-67; Widdowson 2004; Дементьев 2010: 103-123; Чернявская 2018), взаимодействия дискурса с другими элементами («моментами») социальной практики и интегрирования социальной теории в дискурсивное исследование вообще (Chouliaraki \& Fairclough 1999; Fairclough 1992; Scollon \& Scollon 2004; Чернявская 2016).

${ }^{2}$ Наряду с аналогичными ресурсами для женщин - «женскими журналами». 
этого феномена, указывается, что к таковым относятся любые медиа в любых форматах, в которых обсуждается следующий открытый список тем: приготовление и употребление еды и напитков; мода, стиль и уход за собой; обустройство дома, сада, внутреннего и внешнего интерьера; саморазвитие; путешествия; шоппинг и потребление материальных и нематериальных благ (Bell \& Hollows 2005a: 9-10). Одним из ключевых форматов лайфстайл-медиа следует считать гендерно-специфицированные лайфстайл-журналы (Corrigan 1997).

\section{1. Идентичность, социальная типизация и предмет потребления}

Рост количества и популярности лайфстайл-дискурсов, их языковые особенности и их потенциальная роль в конструировании идентичностей предопределяются рядом сдвигов социокультурного характера.

Один из таких сдвигов обсуждается в рамках постмодернистских концепций идентичности. Лейтмотивом этих дискуссий является представление о том, что общество позднего модерна характеризуется появлением новой «рефлексивной» - модели формирования идентичности. Рефлексивность понимается как возможность постоянного анализа и пересмотра социальных практик в свете новой теоретической информации об этих практиках (Chouliaraki \& Fairclough 1999; Giddens 1991). Такому рефлексивному пересмотру подвергается в том числе и представление индивида о себе. Традиции и социальная структура, ранее предопределявшие эти представления, утрачивают приоритетные позиции в данном процессе; формирование идентичности становится «рефлексивным проектом» индивида (Giddens 1991). Иными словами, меняется способ формирования идентичности: идентичность перестает быть «задаваемой» и потенциально становится целенаправленно формируемой или стилизуемой.

Однако каким бы ни был способ формирования идентичности - целенаправленным или каким-либо еще - ее социальная значимость, равно как и возможность ее изучения, базируется на еще одном важном ее качестве способности быть выраженной в конкретных ситуациях социального взаимодействия. Акцент на перформативном характере идентичности и ее понимании как конструируемой в актах коммуникации является определяющим при изучении идентичности в социолингвистике и лингвистической антропологии (Auer 2007; Blommaert 2005; Bucholtz \& Hall 2005; Coupland 2007; Eckert 2008). Базовая идея таких исследований - представление о том, что идентичность должна иметь материальную форму выражения и благодаря этому быть доступна для считывания окружающими (Agha 2007: 233-234; Bucholtz \& Hall 2005). Частью такой материальной формы может быть любой доступный для восприятия и интерпретации объект (Spitzmüller 2015: 128). В социолингвистике семиотическим ресурсом стилизации предсказуемо являются языковые формы. Однако набор ресурсов проекции идентичности, конечно же, не сводится только к языковым. 
Какую же информацию, релевантную для «считывания» идентичности, передает объект, используемый как знак? Такой объект-знак транслирует информацию о некоторой социальной типизащии, в которую включен индивид или на которую он «претендует», используя данный знак. Примером такой типизации могут быть как относительно устойчивые и традиционные категории идентичности, такие как гендер и социоэкономический класс, так и любые другие группы, категории и роли с которыми идентифицируется индивид (Burke \& Reitzes 1981; Jenkins 2004; Stryker \& Burke 2000; Tajfel 1974). К подобным типизациям следует отнести и лингвокультурные типажи (Карасик 2009). В условиях современного (западного) общества потребления, как известно, одним из важных семиотических ресурсов проекции идентичности являются промышленные товары.

То, что потребление связано с выражением определенной социальной типизации, известно давно. Традиционной категорией, выражаемой путем приобретения товаров и участия в коммерциализированных практиках, является социоэкономический класс (Bell \& Hollows 2006b: 9; Corrigan 1997: 162). Такая ситуация в целом может характеризовать и современные паттерны потребления (Rössel \& Pape 2016). С другой стороны, все чаще наблюдается и ситуация, когда потребление опосредовано менее масштабными и менее устойчивыми типизациями (Berger \& Heath 2007; Kleine, Kleine, \& Kernan 1993), в том числе и стилями жизни (Rössel \& Pape 2016).

Стили жизни, как и любые другие шаблоны потребления (например классовые), являются организованными множествами товаров и практик, присваиваемых индивидом, с целью проецирования определенной формы идентичности. Однако, в отличие от классовых предпочтений, стили жизни считаются более-менее свободно и сознательно выбираемыми индивидом (Featherstone 1987). Процесс выбора и воплощения стиля жизни должен характеризоваться большей рефлексивностью, реализовываться в более позднем хронотопе социализации, и требовать специальных информационных ресурсов, регламентирующих нужные лайфстайл-модели. Следовательно, в реализации лайфстайл-проектов одну из ведущих ролей должен играть дискурс. Дискурс же играет одну из ключевых ролей и в превращении товаров в ресурсы стилизации (Agha 2011).

\section{2. Дискурс, лайфстайл-модели и объекты-знаки}

Не сложно заметить, что перечисленные ранее лайфстайл-жанры - уход за собой, кулинарные шоу, шоу по садоводству, обустройству дома и другие по сути являются инструкциями, призванными проинформировать индивида о надлежащем способе реализации этих практик и использовании соответствующих товаров (Bell \& Hollows 2005a; Talbot 2007: 107). Иными словами, одной из основных функций лайфстайл-дискурса следует считать инструктируюшую. Это инструктивность в узком смысле, подчеркивающая аспект 
“how-to” подобных текстов и сближающая их с другими - более традиционными - типами инструкций.

Как было отмечено выше, лайфстайл-дискурс играет важную роль и в еще одном процессе - в наполнении объекта-знака соответствующим социальным смыслом. Естественно, в течение «жизненного цикла» товара хронологически одним из первых дискурсов, решающих задачу такого формулирования, является реклама. В семиотических терминах цель рекламы - создание из товара привлекательного знака для преодоления товаром фазы товарно-денежного обмена (Agha 2011).

Хотя мы не относим рекламу к лайфстайл-дискурсу в обсуждаемом в статье смысле, нельзя отрицать, что современная реклама включает в себя элементы лайфстайл-проектов. Большая часть такой рекламы вместе с рекламируемым предметом потребления также интегрирует в дискурс некоторую совокупность прочих знаков. Это позволяет (1) наполнять содержанием рекламируемый объект-знак в терминах какого-то стиля жизни, а также (2) предлагать «импрессионистский» набросок этого стиля жизни для реализации индивидом в фазе владения товаром. Второй аспект позволяет также приписывать рекламе элемент инструктивности, но уже в чуть более широком смысле. Такая инструктивность выражается в информационной и «обучающей» направленности рекламы, то есть в ее функции формулирования более-менее целостных моделей лайфстайл-проектов. Первый же аспект позволяет говорить о метасемиотической функции этих дискурсов. Как в рекламе, так и лайфстайл-дискурсе уподобляются друг другу (типизируются) разнородные объекты-знаки в их функции выражения определенного социального смысла. Для обозначения такого социального смысла и используется метасемиотический термин, выступающий гиперонимом по отношению к этим объектамзнакам (например для рекламы: «шик», «элегантность» и т. п., см.: Agha 2007: 22, 76, 179, 2011). В нашем случае такой социальный смысл подразумевает реальную или заявляемую принадлежность субъекта к определенному стилю жизни/социотипу.

Однако сегодня реклама вряд ли может считаться оптимальныл источником лайфстайл-моделей и метасемиотических проектов. Это объясняется рядом причин. Во-первых, рекламный дискурс ограничен во времени и пространстве. Традиционные рекламные ролики, как правило, не длятся больше нескольких секунд. В еще большей мере это применимо к печатной рекламе в форме изображения (например, на страницах журнала). Такая ограниченность препятствует «детализации» лайфстайл-проекта, сужает его семиотический диапазон, а также практически исключает инструктивность в узком смысле (то есть аспект how-to). Во-вторых, если допустить, что основными каналами распространения такой рекламы являются телевидение и печатные журналы, то скорее всего следует допустить и то, что контакт изелевой аудитории с такими медиа в настоящее время ограничен ввиду снижения популярности 
обоих указанных видов СМИ, особенно среди молодой аудитории ${ }^{3}$. И самое главное - сложно представить, что кто-либо рассматривает рекламу как дискурс, с которым целенаправленно «ищут встречи»: реклама преимущественно воспринимается как нечто назойливое и как нечто, взаимодействия с чем по возможности избегают (Cook 2001: 203).

В случае собственно лайфстайл-ресурсов все названные ограничения снимаются. Лайфстайл-порталы и каналы YouTube содержат сотни и тысячи статей и видео, имеющих гораздо большую временную и пространственную протяженность. Благодаря этому в метасемиотический диапазон может включаться практически бесконечное количество различных объектов-знаков. При этом эти ресурсы, в отличие от рекламы, являются дискурсами, к которым реципиент обращается «по собственной воле». При этом есть основания полагать, что пропорция населения, рутинно обращающегося к таким дискурсам, растет (см. ниже).

Понятно, что набор стилей жизни и связанных с ними социотипов и форм идентичности потенциально безграничен. В данной работе мы хотели бы остановиться лишь на одном, но достаточно популярном, виде интернетмедиа - новых онлайн-ресурсах для мужчин (НОРМ) ${ }^{4}$ и конструируемым ими набором форм идентичности. Данные ресурсы, по нашим наблюдениям, существуют в трех основных форматах: порталы (то есть сайты, содержащие большое количество дискурсов, создаваемых авторским коллективом), блоги (как правило, принадлежащие одному автору) и каналы YouTube (как правило, принадлежащие одному автору). Хотя инструктивная how-to составляющая будет очевидна во всех приводимых примерах, мы далее акцентируем только метасемиотическую функцию, которая и является предметом изучения.

\section{3. Новые онлайн-ресурсы для мужчин}

\section{1. Материал и метод}

Материалом основного анализа послужили дискурсы порталов "Primer" и “Askmen”5. Для иллюстрации отдельных утверждений на ступени контентанализа и при демонстрации интертекстуальных связей дополнительно используются примеры, взятые с нескольких каналов YouTube ${ }^{6}$.

${ }^{3}$ Cм.: The State of Traditional TV: Updated With Q2 2017 Data-Marketing Charts. (2017). Retrieved October 24, 2018, from https://www.marketingcharts.com/featured-24817.

${ }^{4}$ Такие ресурсы являются наследниками печатных мужских журналов, однако не являются их аналогами. Поэтому для их обозначения мы предлагаем использовать отличный термин. См. также ниже.

${ }_{6}^{5}$ Primer: https://www.primermagazine.com/; Askmen: https://uk.askmen.com/.

6 К основным из них относятся: alpha m. (https://www.youtube.com/user/ AlphaMconsulting/featured), Real Men Real Style (https://www.youtube.com/user/ RealMenRealStyle), Teachingmensfashion (https://www.youtube.com/user/Teachingmensfashion). 
Анализ проводится в соответствии с адаптированной моделью дискурсанализа, предлагаемой дискурс-аналитиками Н. Фэрклафом и Л. Чулиараки (Chouliaraki \& Fairclough 1999: 60-66). Модель предполагает следующие стадии в реализации исследования.

(1) Идентификация проблемы. Исследование начинается с фокусирования на социальной проблеме, по крайней мере часть «проблемности» которой связана с ее дискурсивным выражением.

(2) Исследование дискурса в его экстралингвистической обусловленности. Данная фаза предполагает описание контекста дискурса, отношения дискурса (речевой составляющей) к другим «моментам» социальной практики и другим социальным практикам, а также собственно анализ речевых произведений/текстов. Анализ речевых произведений включает такие шаги, как анализ контента, интертекстуальных связей и анализ лексико-грамматической реализации.

(3) Интерпретация результатов анализа. Интерпретация полученных данных в свете заданных теоретических положений.

\section{2. Контекст}

Новые интернет-ресурсы для мужчин можно рассматривать как наследников традиционных печатных мужских глянцевых журналов (Benwell 2002; Edwards 2003; Jackson Brooks, \& Stevenson 1999; Jancovich 2006; Stevenson, Jackson, \& Brooks 2000). При этом данные виды медиа отнюдь не являются их цифровыми аналогами. Так, например, о различиях НОРМ и традиционных мужских журналов говорит основатель одного из каналов YouTube ${ }^{7}$ данного типа Арон Марино:

...this was back in 2007, and I started looking to see what resources were out there for everyday regular guys like me, like my dad, like my friends, just to get simple, basic style advice and I found that there really wasn't anything. I wanted to help my buddies, and so, I realized that there really wasn't anything out there except at the time, like GQ and Esquire but that wasn't my reality. I didn't understand that level of dress; I didn't understand high fashion and so I decided to create a resource and a solution, and that's how my image consulting business got started. (AlphaM Interview with Aaron Marino 2016)

В 2008 году А. Марино создает свой лайфстайл-канал “alpha m.”: “I made my first one [первое видео для канала. - E. M.], it was like 2 minutes long, the resolution was like $180 \mathrm{p}$ and the rest is history" (Ibid.). На момент написания статьи данный канал является одним из самых популярных и востребованных HOPM на YouTube; количество подписчиков канала составляет более четырех с половиной миллионов человек, а за первую неделю с момента публикации типичный видеоролик набирает примерно 200 тысяч просмотров.

\footnotetext{
${ }^{7}$ https://www.youtube.com/user/AlphaMconsulting/featured
} 
Похожую историю создания ресурса рассказывает и основатель и редактор одного из популярных НОРМ - журнала "Primer", указывая на свою неудовлетворенность существовавшими на тот момент (2008 г.) традиционными лайфстайл-журналами:

When I began, I was recently out of college, trying to get my feet on the ground, but felt like there wasn't anyone talking specifically to me. I was left with tons of scattered media that I had to piece together in what I believe is a very common place in life: that important time after graduation where you'll be making some of the most significant decisions of your life. $<\ldots>$ And surprisingly, I couldn't find help anywhere. I was going through my own quarter-life crisis that is all too common among folks that are 23-30". (Snavely 2018)

Как и канал “alpha m.”, "Primer” был создан в 2008 году. С момента основания его популярность значительно выросла; количество посетителей портала в настоящий момент составляет 600 тысяч человек в месяц 8 .

Обе приведенные цитаты являются метапрагматическими текстами, то есть текстами, содержащими информацию о прагматике других коммуникативных событий (Spitzmüller 2015). В данном случае такие коммуникативные события включают весь дискурс созданных ими впоследствии НОРМ. Оба автора отмечают предназначенность своих дискурсов для заполнения лакун особого рода - компенсации отсутствия нужных инструктирующих дискурсов (ср. there really wasn't anything; couldn't find help anywhere) и релевантных формулировок лайфстайл-моделей (basic style advice; couldn't find help anywhere; there wasn't anyone talking specifically to me), в которых бы фигурировали релевантные же товары/знаки (that wasn't my reality; I didn't understand that level of dress; I didn't understand high fashion; there wasn't anyone talking specifically to me).

Эти же цитаты позволяют идентифицировать и ключевой для НОРМ метасемиотический термин. На роль такого термина должны претендовать формулировки, выражающие семы «маскулинность», «стильный» и «простой/обычный» (ср.: regular guys like me, basic style advice). Обращение к актуальному контенту НОРМ подтверждает данное предположение. К примеру, метапрагматический текст в заголовке домашней страницы на сайте "Primer" гласит:

A GUY'S GUIDE TO GROWING UP. Affordable style, self-development, how-tos, and apartment DIY for the aspiring gentleman'.

${ }^{8}$ Snavely, A. (2018). Win 1 of 3 Pairs of Wolverine 1,000 Mile Boots: Primer Wants to Thank You For 10 Amazing Years. Primer. Retrieved April 24, 2018, from https://www.primermagazine.com/2018/spend/wolverine-1000-mile-giveaway

${ }^{9} \mathrm{https}: / / \mathrm{www}$.primermagazine.com/. Здесь и далее в примерах прописные буквы как в оригинале. 
Помимо акцентирования адресованности простому стильному мужчине (guy's guide, affordable style) и инструктирующей функичи (guide; how-tos, DIY, то есть “do it yourself”), приведенный текст интересен еще и тем, что подчеркивает процесс трансформации идентичности от «незрелого»к «зрелому» (a guy's guide to growing up) и от более «грубого» к «более утонченному» (aspiring gentleman).

Из приведенного примера также очевидно, что лексема gentleman может претендовать на роль одного из ключевых метасемиотических терминов. Действительно, даже поверхностный взгляд на современный контент аналогичных ресурсов подтверждает его популярность. Это утверждение иллюстрируется названиями некоторых каналов данного типа, например Gent's Lounge, Gentlemen's Gazette, The Effortless Gent. Дальнейший обзор названий конкретных дискурсов НОРМ показывает, что в роли метасемиотических терминов фигурируют и другие ярлыки. Все они, однако, выражают разные «ипостаси» маскулинности, противопоставляемые по нескольким векторам:

(a) по линии «зрелость/незрелость»: kid/child vs. man/grown up, ср.: Clothes That Make Men Look Like Boys (Real Men Real Style); 10 Back to School Style Essentials Every Student NEEDS (Teachingmensfashion);

(б) по линии «утонченность/изысканность»: man/guy vs. gentleman (см. выше);

(в) по линии «крутость/уверенность/агрессивность»: man/guy vs. bad boy/bad ass cp.: Bad Boy Summer Style: How to Look Like A Bad Boy (alpha m.).

Как и в случае с женскими журналами (Corrigan 1997: 84), одной из основных характеристик традиционных мужских журналов и НОРМ является то, что со временем все большее количество практик «охватывается» дискурсами, регламентирующими надлежащий образ реализации этих практик ${ }^{10}$. Так, еще в 2003 году Т. Эдвардз, исследовавший традиционные мужские журналы в Британии, отмечал, что открытое обсуждение таких вопросов, как, например, уход за кожей, сохранение ее молодости и увеличение мужской привлекательности вообще, было практически невозможно, а (метасемиотические) термины «стиль» или «мода» употреблялись с большой осторожностью (Edwards 2003). Сегодня же таким темам посвящена значительная часть публикуемых в НОРМ материалов. Например, на канале "alpha m.” данным темам посвящен отдельный плейлист Grooming Tips \& Hacks. В плейлист включены видео с такими названиями, как 5 Grooming Secrets ONLY Handsome Men Know, 5 Surprising Things that Will PERMANENTLY Make You LESS Attractive; Should Guys Shave or Trim Their Legs? А видео How to look more attractive in 30 days за шесть дней с момента публикации набрало 276 тысяч просмотров.

Насколько «далеко может заходить» дискурс в регламентации практик и включении объектов-знаков в метасемиотический диапазон, можно также

10 Такие дискурсы являются рефлексивными и отражают общую тенденцию рефлексивности позднего модерна, обсуждавшуюся выше (Chouliaraki \& Fairclough 1999). 
проиллюстрировать следующим списком возможных how-to: Hold Your Phone Like A Bad-Ass (Real Men Real Style); How To Be A Gentleman: Public Cell Phone Etiquette (alpha m.); How To Eat An Ice Cream Cone Like A Gentleman! (alpha m.); How to walk like a BADASS! (alpha m.). То есть в охват метасемиотического термина (bad-ass, gentleman) включаются такие практики, как обращение с телефоном (hold your phone; public cell phone etiquette), употребление мороженого (eat an ice cream cone like a gentleman) и походка (how to walk).

\section{3. (Интер)дискурс}

Анализируемый далее текст (Guzan 2018) взят с портала “Primer” и является примером «переформулирующего» поджанра. Тексты такого поджанра посвящены обсуждению ошибок стиля: отдельные предметы или их комбинации признаются нестильныли или же наоборот - нестильным предметам и их комбинациям возвращзается статус стильных. Рассматриваемый текст относится ко второму типу.

В тексте обсуждается девять мифов о нестильных вещах и их комбинациях. Рассматриваемый экземпляр имеет типичную для текстов НОРМ структуру. Такая структура в данном случае характеризуется наличием вступления и девяти микротекстов. Каждый микротекст освещает один из аспектов макротемы - один из мифов. Микротексты также снабжены названиями/подзаголовками, называющими конкретный миф. Во вступлении ожидаемо вводится ключевой метасемиотический термин, реализуемый здесь лексемой style и лексемой men, ср.:

Thus, it's important to explore and reevaluate these style norms and bust some of the stuffier rules that have no business informing men's style in 2018. (Guzan 2018)

Непосредственный анализ текста подтверждает сформулированный в предыдущем разделе тезис: для определенных форм идентичности в дискурсе формулируется диапазон ресурсов, при помощи которого эти формы могут быть выражены. Рассмотрим непосредственную динамику этого процесса на примере одного из девяти микротекстов:

[Myth: You should not wear jeans with a tie]. Busted: If you're not in a professional business environment, there's no reason not to explore with balancing class and comfort for a first date, coffee with an old friend, or a spruced-up approach to casual Friday in your creative office. The trick to not looking like you stepped off the set of a 90 s sitcom is to incorporate elements that work together, dressing down the tie with casual knit neckwear and dressing up the jeans by wearing a slim, dark pair. (Guzan 2018)

В приведенном фрагменте обсуждается правомерность применения метасемиотического термина к комбинации объектов-знаков «галстук в сочетании с джинсами» (jeans with a tie). Соотнесение комбинации с термином не 
является прямым: чтобы комбинация считалась стильной, должны выполняться как минимум два вида условий. Так, комбинация рассматривается как уместная в следующих ситуациях: «первое свидание» (a first date), «кофе со старым приятелем» (coffee with an old friend) или так называемая «неформальная пятница» (casual Friday) в «креативном офисе» (creative office). Аналогичным образом налагаются ограничения и на качественные характеристики товаров: наиболее удачным является сочетание вязанного галстука и темных узких джинсов (knit neckwear; a slim, dark pair).

Приведенный пример акцентирует внимание на важной особенности таких (пере)формулирующих дискурсов - роли интертекстуальности в реализации метасемиотического проекта. Ясно, что каждый из микротекстов не является замкнутым, но перекликается с множеством других «голосов»огромным миром лайфстайл-дискурса в НОРМ и, возможно, традиционных мужских журналах. Как минимум каждый из микротекстов в рассматриваемом примере переформулирует правило, предположительно сформулированное «где-то еще», даже если интертекстуальность никак не маркирована в поверхностной структуре ${ }^{11}$. Явной, но тем не менее генерализованной, отсылкой к такому «где-то еще» служит слово $m y t h$, неоднократно используемое в тексте.

С другой стороны, особенностью формата НОРМ является и маркирование интертекстуальных связей. Механизм такого маркирования - использование гиперссылок. Так, например, микротекст Myth: Tie width should be relative to a man's frame сопровождается гиперссылкой на текст 11 Out-of-Style Trends You Should Phase Out of Your Wardrobe и The 8 essential ties for any (and all) occasions. Маркированная гиперссылкой интертекстуальность может даже являться необходимым условием для интерпретации микротекста. Так, например, содержание последнего из девяти микротекстов (Myth: You really don't need to own a black suit) сводится к трем пропозициям: Bust... actually, never mind, we're still pretty sure about this rule. Фрагмент we're still pretty sure отсылает к отдельной статье, где подробно обсуждаются правила выбора цвета костюма.

Такая особенность наилучшим образом иллюстрирует динамический характер дискурсивной «работы»: один и тот же элемент и их комбинации вплетаются в бесконечную цепочку дискурсов, потенциально способных каждый раз наполнять их новым социальным смыслом.

${ }^{11}$ Интересным вопросом является то, был ли такой миф на самом деле сформулирован в интердискурсе. В случае с комбинацией «джинсы-галстук» найденные нами дискурсы формулируют ее как стильную примерно с такими же параметрами, как в приведенном здесь примере (см., например https://cladwell.com/blog/wearing-a-tie-with-jeans-can-you-pull-it-off2). Один из наиболее «старых» дискурсов (2003 г.) формулирует данную комбинацию как ограниченно допустимую, но тем не менее допустимую (см. https:/www.gq.com/story/tiejeans). 


\section{4. Языковые средства}

Рассматриваемый далее текст (Fox n.d.) также относится к поджанру переформулирующих и иллюстрирует его первую вариацию - выведение объектов-знаков из-под термина «стильный». В тексте обсуждается ряд ошибок (things you can't wear), совершаемых мужчинами в возрасте от 30 до 40 лет (in your thirties). Текст воспроизводит типичную жанровую структуру НОРМ: каждый из 10 советов оформлен в отдельный микротекст, снабженный названием/подзаголовком, а сами микротексты предваряются общим вступлением. Анализу ниже подверглись два из десяти микротекстов, однако выдвигаемые положения применимы ко всему тексту.

Предлагаемый анализ иллюстрирует то, как в реализации метасемиотического проекта участвует одна из систем семантики текста - система оценки. Как известно, оценка может быть выражена при помощи комбинации языковых средств, семантическая структура которых, по крайней мере отчасти, определяется собственно оценочным (эмотивным) компонентом. Однако такая ситуация наблюдается не всегда. Часто оценка актуализируется в тексте комбинацией средств с дескриптивной семантикой (Martin \& White 2005: 61 -68). Способы реализации оценки в НОРМ в первом приближении обнаруживают две (взаимозависимых) особенности. Во-первых, оценка играет в НОРМ одну из главных ролей при «наполнении» товаров-знаков нужным содержанием и социальным смыслом. Во-вторых, часто полноценная интерпретация оценки возможна только в том случае, если фреймом интерпретации считать проект «знак-идентичность». Рассмотрим следующий микротекст в составе анализируемого текста:

[Cheap suits] So the inexpensive, off-the-rack suit you had nipped and tucked at the tailor in your 20s ain't gonna cut it anymore. In this round of life, you'll need to pay attention to the richness of the fabric (it should probably come from Italy) and the construction of the garment (full canvas is king). (Fox n.d.)

Единственные явные маркеры оценки в представленном фрагменте номинализация признака richness, используемая для передачи позитивной оценки ткани (fabric), а также выражение is king для оценки покроя костюма (the construction of the garment). Имплицитная оценка усматривается в сочетании дескриптивных языковых средств inexpensive и off-the-rack (негативная оценка по основанию «качество»), а также идиомы nipped and tucked как действий, по всей видимости, применимых к дешевым костюмам ${ }^{12}$. Аналогичным образом положительная оценка прочитывается в сочетании it should

${ }^{12}$ Обыгрывается идиома nip and tuck - разговорное обозначение пластической хирургической операции (ср.: a cosmetic surgical procedure in which skin and usually fat are removed and muscle is sometimes tightened to create a slimmer or more youthful appearance). 
probably come from Italy, являющемся отсылкой к дискурсам, формулирующим итальянское происхождение товара как знак качества и изысканности ${ }^{13}$.

С одной стороны, параметр качества одежды может быть ценностью сам по себе. С другой - в данном контексте оценка товаров наполняется смыслом, только если принять в расчет суть метасемиотического проекта «знакидентичность»: в конечном счете все товары оцениваются исходя из того, насколько успешно они как объекты-знаки могут стать материалом для воплощения правильной идентичности зрелого стильного мужчины.

Ср., также следующий отрывок:

[Anything Graphic or Novelty] Still sporting graphic tees with allegedly ironic phrases or novelty ties with cartoon characters? Life's a bit more serious these days. Grow up and go for solids or subtle patterns on your T-shirts and similarly sophisticated ties in cotton, wool or knitted silk. (Fox n.d.)

В приведенном примере оценка выражается имплицитно через преимущественно дескриптивную лексику (graphic tees, ironic phrases, cartoon characters, solids, subtle patterns, sophisticated ties, cotton, wool, knitted silk) и также подлежит интерпретации в рамках метасемиотического проекта «знакидентичность»: футболки с принтом и/или надписями юмористического содержания оцениваются негативно, поскольку не являются знаками, способными проецировать нужную форму идентичности стильного зрелого мужчины.

\section{4. Результаты и обсуждение}

Рассмотрение контекста возникновения и существования НОРМ, связи их дискурса с другими моментами социальной практики и анализ самого дискурса позволили сформулировать ряд наблюдений.

Одним из моментов социальной практики являются индивиды как носители определенных цеенностей и убеждений (Chouliaraki \& Fairclough 1999). В рассмотренных метапрагматических текстах подчеркивается, что НОРМ возникли как реакция новых культурных посредников на отсутствие ресурсов, формулирующих релевантные метасемиотические проекты.

Лайфстайл-дискурс, и НОРМ в частности, являются рефлексивньлми дискурсивныли практиками, то есть практиками, теоретизирующими другие практики, как дискурсивные, так и недискурсивные (Chouliaraki \& Fairclough 1999). Современные НОРМ теоретизируют достаточно широкий диапазон со-

${ }^{13}$ Например: The phrase 'Italians do it better' has never been truer than when it comes to contemporary menswear. The Milanese tailors of the world have always been ahead of the crowd thanks to a sharp eye for detail, luxury craftsmanship and a sound understanding of how the male body works (https://www.fashionbeans.com/2014/5-mens-italian-clothing-brands-you-shouldknow). 
цзиальных практик, включая и такие, которые интуитивно такого теоретизирования не требуют. Такая ситуация свидетельствует о расширении рефлексивного охвата дискурсов НОРМ по сравнению с аналогичными ресурсами, существовавшими 15-20 лет назад (Edwards 2003; Stevenson et al. 2000) и, скорее всего, по сравнению с теми, что существовали еще раньше.

Один из вариантов исследования собственно дискурса НОРМ - его анализ в рамках метасемиотического подхода (Agha 2007). В терминах данного подхода одной из функций лайфстайл-дискурса является формулирование метасемиотических проектов «знак-идентичность». В таких проектах предметы потребления и реализуемые с их помощью практики формулируются как семиотические ресурсы выражения форм идентичности. При этом суть метасемиотической «дискурсивной работы» может быть определена как типизация, то есть уподобление разнородных объектов-знаков и «прикрепление» их к определенному метасемиотическому термину. Наиболее вероятным кандидатом на роль такого термина является инвариантное «стильный мужчина». Данный термин может быть выражен в тексте открытым списком языковых средств, включая словоформы с корневой морфемой style, а также лексемы, называющие различные «ипостаси» современного мужчины - man, guy, kid, gentleman и bad ass.

Ключевую роль в реализации метасемиотических проектов играет $u н$ тертекстуальность. Рассмотренные микротексты в составе текстов являются акцентированно открытыми, поскольку всегда перекликаются с формулировками метасемиотических проектов «где-то еще», в интердискурсе, подтверждая их, слегка преобразуя или же полностью оспаривая. Тексты также изобилуют маркированными интертекстуальными отсылками, оформленными в виде гиперссылок.

Описанные формы интертекстуальности являются ключевым компонентом реализации метасемиотического проекта: интертекстуальные связи выстраивают дискурсивные цепочки, в которых объекты-знаки и их комбинации подвергаются бесконечному переформулированию. При этом даже немаркированные интертекстуальные связи поддаются отслеживанию при условии знакомства с большим массивом НОРМ. Такое положение дел позволяет позиционировать заявленную выше принципиальную открытость как свойство дискурса, потенциально поддающееся эмпирическому исследованию и описанию, не приравнивая ее к абстрактной «бесконечности безграничного текста».

Анализ метасемиотической «дискурсивной работы» может быть осуществлен и на уровне конкретных лексико-грамматических средств. Примером может служить демонстрация того, как метасемиотический проект «знакидентичность» является релевантным фреймом интерпретации лексико-грамматических средств, выражающих оценку. Такой фрейм - необходимое условие реконструкции оценочной позиции текста/фрагмента и, в частности, 
объяснения того, как преимущественно дескриптивные средства приобретают интратекстовые оценочные свойства.

Проект «знак-идентичность», в котором знаками являются предметы потребления, можно рассматривать как содержательную основу и внутренний механизм так называемого дискурса консьюмеризма или - точнее - дискурса «коммодифицированных идентичностей» (Benwell \& Stokoe 2006) ${ }^{14}$. Такой дискурс - один из основных дискурсов, актуализируемых в НОРМ и лайфстайл-медиа. Следовательно, предложенные в статье анализ и интерпретация вносят вклад в изучение как лайфстайл-медиа, так и в изучение самого дискурса «коммодифицированных идентичностей», а следовательно, консюмеризма и общества потребления вообще. Очевидно, однако, что лайфстайлдискурс апеллирует и к другим дискурсам, связанным с другими практиками, идеологиями и группами субъектов. Этот факт определяет одно из ограничений предложенного исследования, а также формулирует потенциальные задачи для последующих исследовательских проектов.

(C) Е.Н. Молодыченко, 2020

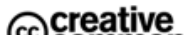
@reative

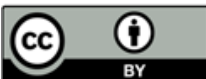

This work is licensed under a Creative Commons Attribution 4.0 International License https://creativecommons.org/licenses/by/4.0/

\section{СПИСОК ЛИТЕРАТУРЫ / REFERENCES}

Арутюнова Н.Д. Дискурс // Лингвистический энциклопедический словарь. 1990. C. 136-137. [Arutyunova, N.D. (1990). Diskurs (Discourse). Lingvisticheskii Entsiklopedicheskii Slovar (pp. 136-137). Moscow: Sovetskaya Entsiklopediya. (In Russ.)].

Дементьев В.В. Теория речевых жанров. М. : Знак, 2010. 600 с. [Dement'v, V.V. (2010). Teoriya Rechevykh Zhanrov (Speech Genre Theory). Moscow: Znak. (In Russ.)].

Карасик В.И. Языковые ключи. М. : Гнозис, 2009. 406 с. [Karasik, V.I. (2009). Yazykovye Klyuchi (The Language Keyes). Moscow: Gnozis. (In Russ.)].

Чернявская В.Е. Дискурсивный анализ и корпусные методы: необходимое доказательное звено? Объяснительные возможности качественного и количественного подходов // Вопросы когнитивной лингвистики. 2018. № 2. С. 31-37. https://doi.org/ 10.20916/1812-3228-2018-2-31-37 [Chernyavskaya, V.E. (2018). Discourse Analysis and Corpus Approaches: A Missing Evidence-Based Link? Towards Qualitative and

${ }^{14}$ Под дискурсом здесь понимается способ семиотического отражения мира с точки зрения определенных групп субъектов. Такое понимание дискурса является одним из основных в критическом дискурс-анализе и, как правило, подчеркивает природу дискурса как идеологически ненейтрального феномена. Это употребление термина «дискурс» следует отличать от его использования в остальном тексте данной работы, где термин «дискурс» понимается в широком смысле как речевой коррелят социальной практики и/или как «текст, погруженный в жизнь» (Арутюнова 1990). 
Quantitative Approaches. Voprosy Kognitivnoy Lingvistiki, 2, 31-37. https://doi.org/ 10.20916/1812-3228-2018-2-31-37. (In Russ.)].

Чернявская В.Е. Прошлое как текстовая реальность: методологические возможности лингвистического анализа исторического нарратива. Вестник Томского государственного университета. Филология. № 3. 2016. С. 76-87. https://doi.org/ 10.17223/19986645/41/7 [Chernyavskaya V.E. (2016). Historical Past as a Textual Reality: a linguistic approach in historical narrative and its methodological implementation. Vestnik Tomskogo Gosudarstvennogo Universiteta. Philologiya, 3, 76-87. https://doi.org/10.17223/19986645/41/7. (In Russ.)].

Agha, Asif. 2007. Language and Social Relations. Studies in the Social and Cultural Foundations of Language. Cambridge: Cambridge University Press. https://doi.org/ 10.1017/CBO9780511618284

Agha, Asif. 2011. Commodity Registers. Journal of Linguistic Anthropology 21 (1). 22-53. https://doi.org/10.1111/j.1548-1395.2011.01081.x

Auer, Peter. 2007. Chapter 1. Introduction. Style and Social Identities. Alternative Approaches to Linguistic Heterogeneity. Berlin/Boston: De Gruyter Mouton. https://doi.org/10.1515/9783110198508.0.1

Bell, David \& Hollows, Joanne. 2005a. Making Sense of Ordinary Lifestyles. D. Bell \& J. Hollows (eds.) Ordinary Lifestyles: Popular Media, Consumption and Taste, 1-18. Open University Press.

Bell, David \& Hollows, Joanne. (eds.) 2005b. Ordinary Lifestyles: Popular Media, Consumption and Taste. Open University Press.

Bell, David \& Hollows, Joanne. (eds.). 2006a. Historicizing Lifestyle: Mediating Taste, Consumption and Identity from the 1900s to 1970s. London and New York: Routledge.

Bell, David \& Hollows, Joanne. 2006b. Towards a History of Lifestyle. D. Bell \& J. Hollows (eds.) Historicizing Lifestyle: Mediating Taste, Consumption and Identity from the $1900 \mathrm{~s}$ to 1970 s, $1-20$. Routledge.

Benwell, Bethan. 2002. Is there Anything "New" about these Lads? The Textual and Visual Construction of Masculinity in Men's Magazines. J. Litosseliti \& L. Sunderland (eds.) Gender Identity and Discourse Analysis, 149-174. Amsterdam, Netherlands: John Benjamins Publishing Company. https://doi.org/10.1075/dapsac.2.09ben

Benwell, Bethan \& Stokoe, Elizabeth. 2006. Discourse and Identity. Edinburgh: Edinburgh University Press.

Berger, John \& Heath, C. 2007. Where Consumers Diverge from Others: Identity Signaling and Product Domains. Journal of Consumer Research 34 (August), 121-134. https://doi.org/10.3174/ajnr.A5382

Blommaert, Jan. 2005. Discourse: A Critical Introduction. Cambridge: Cambridge University Press.

Bucholtz, Mary \& Hall, Kira. 2005. Identity and Interaction: A Sociocultural Linguistic Approach. Discourse Studies 7 (4-5), 585-614. https://doi.org/10.1177/ 1461445605054407

Burke, Peter. J. \& Reitzes, Donald. C. 1981. The Link between Identity and Role Performance. Social Psychology Quarterly, 44 (2), 83-92. https://doi.org/10.2307/3033704

Chaney, David. 2002. From Ways of Life to Lifestyle: Rethinking Culture as Ideology and Sensibility. J. Lull (ed.) Culture in the Communication Age, 75-88. London: Routledge.

Chouliaraki, Lilie \& Fairclough, Norman. 1999. Discourse in Late Modernity: Rethinking Critical Discourse Analysis. Edinburgh: Edinburgh University Press.

Cook, Guy. 2001. The Discourse of Advertising (2nd ed.). London/New York: Routledge.

Corrigan, Peter. 1997. The Sociology of Consumption. An Introduction. London: SAGE Publications. 
Coupland, Nikolas. 2007. Style: Language Variation and Identity. Cambridge: Cambridge University Press.

Eckert, Penelope. 2008. Variation and the Indexical Field. Journal of Sociolinguistics 12 (4). 453-476. https://doi.org/10.1111/j.1467-9841.2008.00374.x

Edwards, T. 2003. Sex, Booze and Fags: Masculinity, Style and Men's Magazines. The Sociological Review 51 (S1). 132-146. https://doi.org/10.1111/j.1467-954X.2003. tb03607.x

Fairclough, Norman. 1992. Discourse and Social Change. Cambridge: Polity.

Featherstone, Mike. 1987. Lifestyle and Consumer Culture. Theory, Culture \& Society 4 (1). 55-70. https://doi.org/10.1177/026327687004001003

Giddens, Anthony. 1991. Modernity and Self-Identity: Self and Society in the Late Modern Age. Stanford University Press. https://doi.org/10.1111/1467-9566.ep11343722

Jackson, Peter, Kate Brooks \& Nick Stevenson. 1999. Making Sense of Men's Lifestyle Magazines. Environment and Planning D: Society and Space 17 (3). 353-368. https://doi.org/10.1068/d170353

Jancovich, Mark. 2006. The Politics of Playboy: Lifestyle, Sexuality and Non-Conformity in American Cold War Culture. D. Bell \& J. Hollows (eds.) Historicizing Lifestyle: Mediating Taste, Consumption and Identity from the 1900s to 1970s.

Jenkins, Richard. 2004. Social Identity. London/New York: Routledge. https://doi.org/10.4324/9780203292990

Kleine, R.E., Kleine, S.S. \& Kernan, J.B. 1993. Mundane Consumption and the Self: A SocialIdentity Perspective. Journal of Consumer Psychology 2(3). 209-235. https://doi.org/10.1016/S1057-7408(08)80015-0

Lüders, Marika, Lin Prøitz \& Terje Rasmussen. 2010. Emerging Personal Media Genres. New Media \& Society 12 (6). 947-963. https://doi.org/10.1177/1461444809352203

Machin, David \& van Leeuwen, Tristan. 2007. Global Media Discourse: A Critical Introduction. London: Routledge.

Martin, James. R. \& White, P.R.R. 2005. The Language of Evaluation. London: Palgrave Macmillan UK. https://doi.org/10.1057/9780230511910

Raisborough, Jayne. 2011. Lifestyle Media and the Formation of the Self. Houndmills: Palgrave Macmillan UK. https://doi.org/10.1057/9780230297555

Rössel, Jorg \& Pape, Simone. 2016. Who has a Wine-Identity? Consumption Practices between Distinction and Democratization. Journal of Consumer Culture 16(2). 614-632. https://doi.org/10.1177/1469540514536192

Scollon, Ron \& Scollon, Suzie Wong. 2004 Nexus Analysis: Discourse and the Emerging Internet. London/New York: Routledge. https://doi.org/10.1111/j.1360-6441.2006. 00321b.x

Spitzmüller, Jurgen. 2015. Graphic Variation and Graphic Ideologies: A Metapragmatic Approach. Social Semiotics 25 (2). 126-141. https://doi.org/10.1080/10350330.2015. 1010323

Stevenson, Nick, Peter Jackson \& Kate Brooks. 2000. The Politics of 'New' Men's Lifestyle Magazines. European Journal of Cultural Studies 3 (3). 366-385. https://doi.org/ $10.1177 / 136754940000300301$

Stryker, Sheldon \& Burke, Peter. J. 2000. The Past, Present, and Future of an Identity Theory. Social Psychology Quarterly 63 (4). 284-297. https://doi.org/10.2307/2695840

Tajfel, Henri. 1974. Social Identity and Intergroup Behaviour. Social Science Information/Sur Les Sciences Sociales 13 (2). 65-93. https://doi.org/10.1177/053901847401300204

Talbot, Mary. M. 2007. Media Discourse: Representation and Interaction. Edinburgh University Press. 
Widdowson, Henry. G. 2004. Text, Context, Pretext: Critical Issues in Discourse Analysis. Malden, MA: Blackwell Publishing Ltd. https://doi.org/10.1002/9780470758427

\section{Список источников иллюстративного материала}

AlphaM Interview with Aaron Marino - Gentleman's Gazette. (2016). Retrieved April 23, 2018, from https://www.gentlemansgazette.com/alpham-interview-aaron-marino/

Fox, A. (n.d.). 10 Things You Can't Wear In Your 30s - AskMen. Retrieved June 6, 2018, from https://uk.askmen.com/fashion/galleries/10-things-you-can-t-wear-in-your-30s.html

Guzan, N. 2018. 9 Menswear Myths Debunked - Primer. Retrieved April 23, 2018, from https://www.primermagazine.com/2018/learn/menswear-myths

Snavely, A. 2018. About - Primer. Retrieved April 23, 2018, from https://www.primermagazine.com/about

\section{Article history:}

Received: 17 May 2019

Revised: 23 September 2019

Accepted: 29 September 2019

\section{История статьи:}

Дата поступления в редакцию: 17 мая 2019

Дата принятия к печати: 29 сентября 2019

\section{Bionote:}

EVGENI N. MOLODYCHENKO is $\mathrm{PhD}$, Associate Professor at Higher School of Economics National Research University (Department of Foreign Languages). Research interests: Critical discourse analysis, persuasion, linguistic axiology, sociolinguistics, text linguistics, stylistics, poetics, rhetoric.

\section{Contact information:}

E-mail: emolodychenko@hse.ru

SPIN-RSCI: 7650-0900

ORCID: 0000-0003-4852-6741

ResearcherID: K-3832-2015

Scopus AuthorID: 56642765800

\section{Сведения об авторе:}

ЕВГЕНИЙ НИКОЛАЕВИЧ МОЛОДЫЧЕНКО — кандидат филологических наук, доцент Национального исследовательского университета «Высшая школа экономики» (департамент иностранных языков). Сфера научных интересов: критический анализ дискурса, персуазивность, лингвистическая аксиология, социолингвистика, лингвистика текста, стилистика, лингвистическая поэтика, риторика.

Контактная информация:

E-mail: emolodychenko@hse.ru

SPIN-RSCI: 7650-0900

ORCID: 0000-0003-4852-6741

ResearcherID: K-3832-2015

Scopus AuthorID: 56642765800 